\title{
Communication modes in collaboration: an empirical assessment of metaphors, visualization, and narratives in multidisciplinary design student teams
}

\author{
Daniel Graff $^{1}{ }_{(D)} \cdot$ Mark A. $_{\text {Clark }}^{2}$
}

Accepted: 21 December 2017/Published online: 29 January 2018

(C) The Author(s) 2018. This article is an open access publication

\begin{abstract}
Universities increasingly incorporate multidisciplinary design projects into their curriculum to better prepare their students for the labor market. In these projects, student team members of various disciplinary backgrounds develop new product or service concepts for organizational partners. This structure enables students to learn not only from the interaction with the content and lecturer, but also from communication with other team members. Little is known, however, about the relative effectiveness of specific communication modes on improving student learning outcomes in these interactions. This study examines the effect of three important communication modes-metaphors, visualizations, and narratives - on reported learning from other members. A total of 64 students working on two large multidisciplinary design student teams participated in this study. Survey results indicate that perceived learning increases through awareness and use of metaphorical communication, beyond previously supported effects for narratives and visualization. We conclude with implications for the way information is represented and structured within multidisciplinary design student teams, and future research directions.
\end{abstract}

Keywords Communication $\cdot$ Learning $\cdot$ Multidisciplinary design teams $\cdot$ Collaboration

Daniel Graff

d.graff@lboro.ac.uk

Mark A. Clark

mark.clark@american.edu

1 Institute for Design Innovation, Loughborough University London, 3 Lesney Avenue, The Broadcast Centre, Queen Elizabeth Olympic Park, London E15 2GZ, UK

2 Kogod School of Business, American University, 4400 Massachusetts Avenue NW, Washington, DC 20016, USA 


\section{Introduction}

Many university programs include courses in their curriculum, in which multidisciplinary design student teams work together in a project-based learning exercise to solve a design challenge (e.g. Gruenther et al. 2009; Miller and Summers 2013). The multidisciplinary team structure and design processes are meant to allow students to take a holistic approach to the project (McMahon and Bhamra 2016), learning from each other's diverse backgrounds (Design Council 2007). This learning (defined via Kraiger et al. 1993 as a multidimensional construct, which is evident from changes in cognition, affective, or skill capacity) occurs through members interaction and collaboration (Jassawalla et al. 2009), specifically facilitated through the use of efficient communication modes among the student members to acquire, share, and combine their unique knowledge (Argote et al. 2012; Silberstang and London 2009). However, as communication across disciplinary boundaries is often difficult (Cho et al. 2015; Dougherty 1992), it is not clear which communication mode may best facilitate learning.

Communication mode refers to the type or manner in which information transmitted among entities is represented and structured. Separate literature streams have identified modes of narratives, visualizations, and metaphors as distinct means of acquiring, sharing, and combining knowledge (e.g. Casakin 2007; Eppler and Platts 2009; Zurlo and Cautela 2014). ${ }^{1}$ These modes have not, however, been empirically investigated together in multidisciplinary design student teams.

In this study, we apply these modes to design and technology education, suggesting that each communication mode will enhance individual learning in multidisciplinary design student teams. We believe that narratives enhance learning through providing context for knowledge concepts, while visualizations illustrate information important for learning. We add to the understanding of communication modes on learning by suggesting that metaphors, through their explanatory and persuasive capacity, will be effective in conveying knowledge across disciplines, thus enhancing individual learning. To determine this added effect, we study these different communication modes together.

This study contributes to the literature by identifying and examining metaphors and their relationship to learning. Existing research has identified important communication skills of active listening, oral, written, and nonverbal expression (cf. Bedwell et al. 2014), but lacks precision with respect to what specific modes of communication can support individual learning in these teams. Particularly, the use of metaphors has been relatively understudied in design teams, and what research exists (e.g. Casakin 2012) does not focus on internal team communication nor associated individual learning outcomes. Further, extant studies of communication modes in design teams have typically examined only one communication mode at a time, such as narratives (e.g., Zurlo and Cautela 2014), sketching and other visualizations (e.g., Eppler and Platts 2009).

In addition, this study contributes to the literature methodology by focusing on the dyadic level within the team, on communication between each pair of members that allows for a more comprehensive and precise picture than what can be seen at the aggregated team level (Espinosa and Clark 2014). For example, communication of metaphors may be used

\footnotetext{
1 The literature often distinguishes between analogy and metaphor. Although all analogies are also metaphors, not all metaphors are analogies (for a discussion see Gentner et al. 2001). Whereas analogies require linkage between the source and the target through relational information, the source and the target in metaphors can be linked through relational information, common attributes, or both (Gentner et al. 2001; Gentner et al. 1988). As all analogies are also metaphors, we use the more inclusive term of "metaphor."
} 
unevenly by dyads and cliques within the design team, which could affect individual learning in a way that would not be captured in a team level study.

In the following section, we will discuss the literature on learning in multidisciplinary teams and the communication modes of interest, leading to our research questions. Specifically, we propose that metaphors, beyond the effects of narratives and visualization, can enhance communication in multidisciplinary design teams engaging in problem-focused discussions, which positively relates to perceptions of individual learning. We then outline our methods employed to collect data, testing these research questions. This is followed by the results section and general discussion. We conclude with implications of the findings for design and technology education, including future directions and limitations.

\section{Learning in project-based multidisciplinary design student teams}

Individual learning can be categorized both as process and outcome (Wilson et al. 2007). As a process, student learning in project-based assignments can occur in different interactions. Learning can occur during student-to-student interactions, student-to-teacher interactions, and student-to-content interactions (c.f. van Breukelen et al. 2017). The learning outcomes of these interactions comprises a multidimensional construct which manifests from changes in cognition, affective, and/or skill capacity (Kraiger et al. 1993). This construct may include changes in quantity and type of knowledge, as well as the relationships among knowledge elements (cognitive learning outcomes), outcomes concerned with the development of technical and motor skills (skill-based learning outcomes), and variations to attitudes (affective-based learning outcomes) (Gagne 1984; Kraiger et al. 1993). In this study, because we examine how communication modes of narratives, visualizations, and metaphors influence individual learning outcomes across student-tostudent interactions, we measure self-reports from the member who is assessing the effectiveness of these communication modes.

One important way that learning occurs is through sharing differential information among team members across disciplines and backgrounds (Clark et al. 2000; Argote et al. 2012; Silberstang and London 2009). Yet, within multidisciplinary teams, communication of knowledge can be problematic. Dougherty (1992) suggested that departments are like thought-worlds that hinder synthesis of the diverse knowledge in multidisciplinary innovation projects. 'Thought-world' refers to a community of people (e.g. a department) who share a common understanding of their domain-specific activities (Douglas 1987). The concept of thought-worlds includes the fund of knowledge (what the individuals within the thought-world know) and the system of meanings (how they know) (Dougherty 1992, p. 182). Each department or thought-world makes sense of the various aspects within an innovation project on the bases of these two elements (Dougherty 1992).

Similarly, graduate students are likely to have acquired a fund of knowledge, as well as a system of meaning, through their basic bachelor-degree education (i.e., thought-world) in their discipline-specific university. This should make communication and learning more difficult than for those without pre-established disciplinary-specific mental models. Accordingly, in the following sections we discuss how communication modes of narratives, visualizations, and metaphors operate in multidisciplinary design teams and relate to individual perceived learning. 


\section{Narratives}

A narrative is a "representation of set of events meaningfully connected in a temporal and causal way" (Onega and Landa 1996, p. 6), creating or describing a broad context or story that makes sense of otherwise disjointed information (Zurlo and Cautela 2014). Lloyd (2000) identified four uses of such narrative storytelling in the design process: (1) providing information about project progress, (2) making sense of past events, (3) as competing rationales for objects, and (4) as a meta story of the design process itself. As such, narratives can steer the design process and influence the design team and its process (Turner and Turner 2003). Narratives can give a much deeper description of events than mere objective documentation of discrete facts, which may help organizations to discover where aspects of knowledge may be acquired and how to share it (Orr 1990; Patriotta 2003).

For individuals, narratives provide a frame to interpret and use information and processes (Zurlo and Cautela 2014) to shape the design experience and establish limits on the focus of information for existing or new ideas. This effectively provides both a support and boundary for knowledge sharing and creation (Patriotta 2003), giving cues for the uses of knowledge in the design process. Designers engaging in narrative explanations may be, as described above, organizing and applying their source information into an edifying framework, thus increasing their understanding according to that frame. Their use of this framework may lead them to believe that they have learned new information or ideas, when compared to the narrative that they have been given. Therefore, we believe that narratives as a communication mode operate through framing the context for individual understanding in the design process, and thus will be positively associated with individual learning.

\section{Visualizations}

Visualizations, as "the use of non-mental images to enhance insights" (Waisel et al. 2008, p. 353) move beyond the design context to address specific information and processes through depictions such as images, drawings, graphs, and animations. Designers use visualizations, such as drawings, sketches, models, and prototypes (for a taxonomy see Pei et al. 2011) to enhance understanding about the task, improve problem solving, as well as a tool to boost creativity (Booth et al. 2016; Do et al. 2000). The positive effects on the design process may stem from the effect of visualizations in facilitating synthesis, improving perspective taking and comparison, and in enhancing comprehension (Eppler and Platts 2009).

As relatively rich media instruments, visualizations may carry more information among the communicants in a design process (Daft and Lengel 1984), operating through expanding the perspectives and channels typically considered (Carlson and Zmud 1999). This expansion may appeal to the cognitive, social, and emotional needs of design participants (Eppler and Platts 2009), providing more avenues for processing this information from various design participants and their perspectives (Hinsz et al. 1997), interpreting and integrating it each member's schematic frame (Clark et al. 2000). In this way, visualizations stimulate the design process by increasing an individual's beliefs about his/her own understanding, through incorporating and applying diverse sets of information and so enhance individual learning. 


\section{Metaphors}

On a very basic level, metaphors convey knowledge by linking a source and target through their structural underlying similarities (Gentner et al. 2001), bridging differences that may otherwise impede use of the dissimilar comparators. Design research has largely focused on metaphors for their potential to solve ill-structured, non-routine problems (e.g. Casakin 2012; Hey et al. 2008), including their use in service and product development (e.g. Ball and Christensen 2009; Ball et al. 2004; Casakin and Goldschmidt 1999; Christensen and Ball 2016; Moreno et al. 2014). In particular, the design-by-analogy approach has received substantial attention, in which designers draw from previous experience to solve problems or create new products (Moreno et al. 2014). When there is not a known solution, a designer is typically aware only of the source and applies this knowledge to an unknown target (see for example the definition of metaphor in Hekkert and Cila 2015).

Metaphors, however, can also be used in design contexts, especially within multidisciplinary design teams, to convey knowledge. Metaphors can be used to describe new concepts or ideas to the recipient (Bearman et al. 2007), and are thus useful for improving understanding of new situations and problems (Kalogerakis et al. 2010). Because metaphors can also be used to transfer new ideas, information, and knowledge, they are closely linked to learning (Loewenstein et al. 2003). Individuals may learn by relating new information to something that they already know (Gregan-Paxton and John 1997). The effectiveness of metaphors in learning has been studied in the marketing literature with respect to how consumers learn about new products (Gregan-Paxton and John 1997) as well as in the education literature (Loewenstein et al. 2003).

In addition, metaphors can also be used to persuade (Gentner 1998). Metaphors are a powerful rhetorical tool that can enhance argumentation by evoking emotions (Pollack 2014), which can override reasoning on the subconscious level and thus potentially persuade others (Pollack 2014). This potential for persuasiveness has been studied mostly in political discourse (e.g. Blanchette and Dunbar 2001) and consumer research (e.g. Goode et al. 2010), to justify design decisions (Madsen 1994) and more recently in the context of multidisciplinary teams and conflict (Paletz et al. 2013).

We suggest two main ways in which metaphors and learning are related. First, metaphors can improve communication between persons by building bridges between thoughtworlds, thereby improving learning in terms of increased knowledge held and individual beliefs about their own knowledge. Second, through the use of metaphors individuals make their knowledge more acceptable to the receiver, thus increasing the likelihood that the knowledge is internalized, and learning occurs. Below, we further elaborate how metaphors enhance learning in multidisciplinary design student teams.

First, we suggest that metaphors as a communication mode are associated with improved sharing of knowledge in task-related mental models, supporting increased understanding and individual learning. Transactive memory system research has shown that communication effectiveness is important in understanding task-related mental models in teams (Lewis 2004) and metaphors are able to improve understanding of project and task requirements in design projects (Kalogerakis et al. 2010). Improved communication through metaphors should enhance the fundamental learning process that includes the sharing, storing, and retrieval of information (c.f. Hinsz et al. 1997) and is therefore related positively to learning (c.f. Argote et al. 2012; Silberstang and London 2009).

Metaphors can also make discipline-specific knowledge more understandable, reducing the potential negative effect of thought-worlds on the learning process. Metaphors can help 
to decontextualize knowledge, enhancing knowledge transfer and learning, which may otherwise fail when knowledge is not transferred because receivers do not understand the relevant knowledge or think it is not applicable in their context (Argote and Epple 1990). For example, design students in multidisciplinary product development teams may link their understanding of the task requirements to knowledge related to product development and thereby transfer underlying structural similarities rather than discipline specifics. Once the decontextualized knowledge is transferred, the team members can apply it to the new situation (or recontextualize it) and thereby learn (Loewenstein et al. 1999).

Some research has indicated that metaphors may also lead to misunderstandings (Haglund 2017; Kampourakis 2016). Recipients of an offered metaphor may have some, but not all information about the metaphor. Therefore, they might misinterpret the metaphor's meaning, so potentially be convinced of something that is not true (Haglund 2017). Further, metaphors may highlight certain aspects of a relationship while downplaying others (Haglund 2017). This could lead to partial or incomplete learning. However, this misunderstanding may be resolved by further explanations, and metaphors may also start a goal oriented discussion which may potentially lead to a more complete and holistic understanding of the metaphor (as discussed by Kalogerakis et al. 2010).

Second, we suggest that by virtue of their potential persuasive power, metaphors increase individual perceived learning. Learning as an outcome requires behavioral or knowledge changes by the receiver (Edmondson 1999). Hence, knowledge, as described above, must not be merely exchanged, but also internalized. Metaphors can support internalization of knowledge through its persuasive function. Political and consumer research has found that metaphors are often used to persuade voters and consumers (Goode et al. 2010). Metaphors are able to evoke emotions that make their argumentation more acceptable (Pollack 2014). In consumer research, metaphors have been shown to influence consumers about new product experience (Goode et al. 2010). These metaphors link the product to a familiar experience and thus influence consumers by shifting their focus to emotional information related to the product (Goode et al. 2010). The persuasive use of metaphors should improve learning outcomes through better knowledge internalization. Therefore, we believe that the use of metaphors in multidisciplinary design student team communication has a positive relationship with member perceptions of their own individual learning.

\section{Research questions}

The overall purpose of this study is to examine the relationship of three distinct communication modes on learning in multidisciplinary design student teams. More specifically, the research questions were as follow:

1. Does the use of narratives in multidisciplinary design team communication have a positive relationship with member perceptions of their own individual learning?

2. Does the use of visualizations in multidisciplinary design team communication have a positive relationship with member perceptions of their own individual learning?

3. Does the use of metaphors in multidisciplinary design team communication have a positive relationship with member perceptions of their own individual learning, beyond the effect of narratives and visualizations? 


\section{Method}

\section{Context}

Empirical data were collected from graduate students as part of multidisciplinary design student teams working with external clients in a design-thinking course taught at universities in Finland and China. The teams' task was to complete an intensive 2-week newconcept development project with a local client organization. In each of the courses, the class of students worked as one multidisciplinary design team that was further divided into several subteams. The client organization expected one overall outcome and the majority of the course grade depended on the performance of the entire team. In general, the project briefs provided in the beginning of the project required the teams to develop service concepts for an external stakeholder. In the Finnish course, the aim was to develop new and improved service concepts for boarding at an airport and in China the project's goal was to improve educational services for a subunit of the university. Each subteam was assigned a subproject that they had to link with the other subtasks to present one holistic outcome. The design teams worked together with the client organization to determine the scope and outcome of the project.

The subteams were formed by the students themselves; they included students from several disciplines (mostly from design, business, and science) and varied in gender, country of origin, and other background characteristics. After the teams were formed, the lecturer informed the students about the project task and subtasks. The student teams chose their own subtask after which no changes in team membership or assignment were permitted. The project ran parallel to lectures that provided the students with the tools and techniques needed for the project. The lectures included design research, creativity techniques, prototyping, business modeling, and communication. Within the communication lecture, among other topics, students were familiarized with various communication modes, including narratives, visualization, and metaphors. All teams produced a mid-term report and a final set of deliverables (the exact deliverable varied and depended on the client's need).

\section{Research design}

This study focuses on individual learning through dyadic communication relationships among team members in multidisciplinary design teams, on the basis that information, assistance, and guidance that are important for learning flow mainly through dyadic relationships (c.f. Argote et al. 2012; Silberstang and London 2009). Also, the focus on individual learning through dyadic communication ties allows for a more comprehensive understanding of the relationship between communication mode and learning compared with the aggregated team level, which might provide an incomplete picture should metaphors be used unevenly within the team (Espinosa and Clark 2014).

The responses were collected by means of the one-with-many design method, where each respondent reports on several dyadic relationships (Kenny et al. 2006) (see Fig. 1 for the structure). Consequently, the level of analysis is the individual and his or her perceived dyadic communication relationships. We used both sociometric and egocentric techniques to collect data (Wasserman and Faust 1994). First, we asked all respondents to report all subteam members, regardless of their frequency of interaction. A potential weakness of this sociometric method is that the dyads reported might define boundaries that were too 


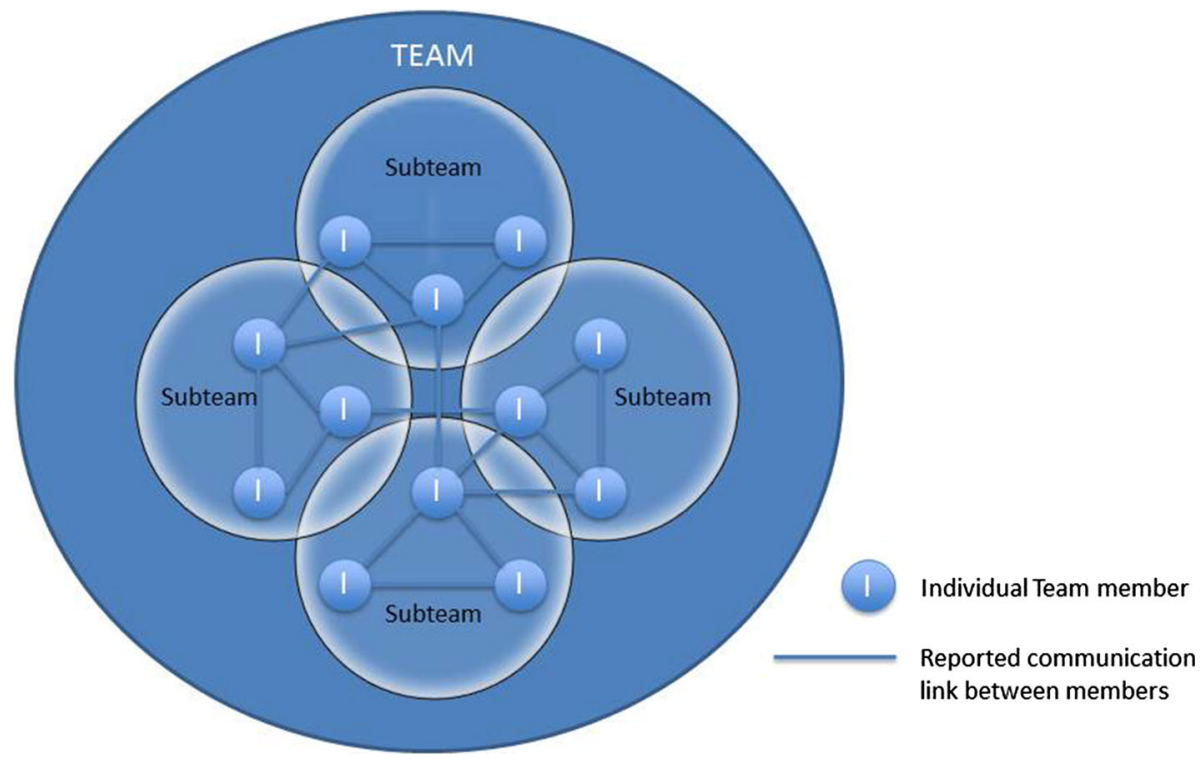

Fig. 1 Structure of the sample

small if team members interacted frequently outside of their subteam (Reagans and McEvily 2003). Hence, we also gathered responses using the egocentric approach by asking respondents to identify the three additional members in the team to whom they had talked most frequently (Reagans and McEvily 2003). Since the sampling technique was based on communication frequency, we eliminated the need to control for the potential motivational effects on learning processes and outcomes.

This design necessitates controlling for individual respondents providing multiple responses, which violate the independence assumption in ordinary least squares regression (Kenny et al. 2006). For example, this violation could occur if a respondent consistently reports a lower-level use of communication modes, creating correlations between error terms among the observations (Reagans and McEvily 2003). To overcome this correlation, we utilize a linear mixed-effects model in which the intercept is random, through a multilevel design in which the respondent represents the higher level and the relationships lower level (Kenny et al. 2006).

We collected data at two points of time, including baseline member attributes (demographics and member familiarity) in a survey completed at the beginning of the course, while process and outcome-related variables, included communication modes and learning, were collected separately, at the end of the course. Both surveys were paper-and-pencil based. The participants were told that the study was about team knowledge processing and that the results would help to improve future concept development project teams. Neither the client organization nor the teams were aware of the specific hypotheses. Naturally, we guaranteed confidentially for all participants, including reporting data only in aggregated form. 


\section{Sample}

Our target population included 78 students in two courses (each with 39 students), who were divided into 16 subteams (Sample 1 consists of seven subteams in Finland; Sample 2 consists of nine subteams in China). Out of the 78 participants invited to take part in the research 64 participated (35 from the Sample 1 and 29 from Sample 2) in the research ( $82 \%$ response rate). The respondents recorded 305 dyadic relationships, which is an average of 4.8 dyads per respondent. The participants were informed that the research concerned team processes and that future courses would benefit from the survey. During the second half of the project, we collected data on background information, communication mode (e.g. narrative, visualization, and metaphor), and learning.

\section{Measures}

All items in the survey were measured with a seven-point Likert scale, ranging from 1 (never) to 7 (very frequent). For each of the identify members of the respondents, we asked: I learnt a lot from the interaction with this person. This item was also measured on a Likert scale from 1 (nothing) to 7 (very much). Using self-reported measures of learning is appropriate for this study, considering that our research questions focus on the member assessment of the effectiveness of particular communication methods in helping them to understand less-familiar concepts. Additionally, self-reported learning measures are common in the educational literature (e.g. Lim and Morris 2006; van Breukelen et al. 2017; Zhao et al. 2005) and are considered appropriate for contexts as student-to-student learning in the Management literature as well (c.f. Benbunan-Fich 2010).

The independent variables were measured by asking the respondent how frequently metaphors, narratives, and visualizations were used in their communication with each of the identified members. We used a single measure approach due to one-with-many research design; this is standard, accepted practice in social network studies (Fliaster and Schloderer 2010; Reagans and McEvily 2003). While multiple item measure for variables might increase reliability, they might also be expected to hamper response rate in research designs where members are expected to rate multiple others with the same measures (Venkataramani and Dalal 2007).

It is important to account for other effects on learning, including member knowledge that may be held in common due to their personal backgrounds. The more common knowledge the dyads have, the lower the costs of transferring knowledge between them in a communication transaction (Reagans and McEvily 2003). According to Reagans and McEvily (2003), various demographic factors such as gender, nationality, and discipline can indicate overlapping knowledge. Hence, we controlled for gender, nationality, and discipline background. We created a dummy variable of 1 and 0 to control for demographic effects on the mode of communication and learning. The same nationality, gender, and discipline of the dyads are equal to 0 or otherwise 1. Furthermore, strong subteam identities can result in-group preference, which may strengthen internal learning. Accordingly, we controlled for subteam membership and created a dummy variable: 1 indicating a different subteam, 0 indicating the same subteam. 


\section{Results}

Independent $t$ tests indicated that the means of the each of the variables in the two data sets were significantly different $(p<0.01)$. Consequently, the data were analyzed separately. Although each sample was of sufficient size on its own (Kreft and de Leeuw 1998), by some estimates the smaller data set, Sample 2, could have had undersized second level variances in the standard error (Maas and Hox 2005). However, studying these phenomena in two different data sets (including a larger Sample 1) with very similar results, provides confidence that the effects found are genuine.

The means, standard deviations, and correlations among all variables in the model are shown for each sample, respectively, in Tables 1 and 2. Note that the correlation tables must be examined with caution, because simple correlations and significance levels indicated cannot consider the dependent nature of the observations (Quigley et al. 2007).

In order to test the hypotheses, we ran a five-step hierarchical linear mixed-effects model for both samples. This approach allowed us to statistically isolate the communication modes to examine their individual strength. In the first step, the base model, only the control variables (subteam, gender, nationality, functional background) and the independent variables perceived individual learning were entered. In the second step, a random intercept was created as a dummy variable for each participant to control for the dependencies of observations (Kenny et al. 2006). In the following steps, the independent variables narratives (Model 3), visualization (Model 4) and metaphors (Model 5) were entered. The hierarchical entry allows examining whether additional variance is explained by the added entry and is indicated by a significant improvement of the model and significant variance between the added entry and the outcome variable. In other words, it allows us to discriminately assess the relative strength of our independent variables. Table 3 displays the regression results for sample 1 and Table 4 the results for sample 2 .

The log-likelihood improved significantly $(p<0.001)$ for each of the incremental models in sample 2, indicating that each communication mode had a unique contribution in explaining perceived learning. In sample 1 all models showed a significant improved loglikelihood $(p<0.001)$, besides of model 4 , when entering visualization.

The final model representing sample 2 , where narratives $\mathrm{F}(1,104.22)=4.16, p<0.05$ and visualization $\mathrm{F}(1,122.85)=4.66, p<0.05$ had a positive relationship with perceived learning, these effects were non-significant in the sample 1 . There narrative $\mathrm{F}(1$,

Table 1 Means, standard deviations, and correlations of all variables-Sample 1

\begin{tabular}{|c|c|c|c|c|c|c|c|c|c|c|}
\hline & & Mean & $\mathrm{SD}$ & 1 & 2 & 3 & 4 & 5 & 6 & 7 \\
\hline 1 & Gender & .59 & .49 & & & & & & & \\
\hline 2 & National & .79 & .41 & $.10 *$ & & & & & & \\
\hline 3 & Discipline & .63 & .48 & $-.09 *$ & $.02 * *$ & & & & & \\
\hline 4 & Subteam & .30 & .46 & $-.01 *$ & $-.10 * *$ & $-.30 * *$ & & & & \\
\hline 5 & Metaphor & 4.01 & 1.42 & $-.04 *$ & $.15^{* *}$ & .05 & $-.06^{*}$ & & & \\
\hline 6 & Visualization & 4.11 & 1.68 & .04 & $-.03 * *$ & .03 & $-.13^{*}$ & $.31 * *$ & & \\
\hline 7 & Narrative & 4.11 & 1.53 & .05 & $.02 * *$ & .00 & -.04 & $.41 * *$ & $.39 * *$ & \\
\hline 8 & Learn & 5.03 & 1.22 & .01 & $.13 * *$ & .14 & $-.16^{*}$ & $.44 * *$ & $.25^{* *}$ & $.32 * *$ \\
\hline
\end{tabular}

$\mathrm{N}=167 ; * p<.05 ; * * p<.01$ 
Table 2 Means, standard deviations, and correlations of all variables-Sample 2

\begin{tabular}{|c|c|c|c|c|c|c|c|c|c|c|}
\hline & & Mean & SD & 1 & 2 & 3 & 4 & 5 & 6 & 7 \\
\hline 1 & Gender & .54 & .50 & & & & & & & \\
\hline 2 & National & .30 & .46 & $.16^{*}$ & & & & & & \\
\hline 3 & Discipline & .45 & .50 & $.21 *$ & $.61 * *$ & & & & & \\
\hline 4 & Subteam & .42 & .50 & $-.22 * *$ & $-.44 * *$ & $-.47 * *$ & & & & \\
\hline 5 & Metaphor & 4.72 & 1.80 & $.08^{*}$ & $.06^{* *}$ & .07 & $-.19^{*}$ & & & \\
\hline 6 & Visualization & 5.47 & 1.55 & .11 & $.06^{* * *}$ & .08 & $-.27 *$ & $.48 * *$ & & \\
\hline 7 & Narrative & 5.12 & 1.59 & .06 & $-.06^{* *}$ & -.02 & -.09 & $.49^{* *}$ & $.54 * *$ & \\
\hline 8 & Learn & 5.90 & 1.21 & .06 & $.02 * *$ & .05 & $-.19 *$ & $.54 * *$ & $.43 * *$ & $.39 * *$ \\
\hline
\end{tabular}

$\mathrm{N}=138 ; * p<.05, * * p<.01$

$135.01)=3.38, p=0.07$ and visualization $\mathrm{F}(1,165.71)=3.22, p=0.07$ showed a nonsignificant relationship with learning. The relationship between metaphor and perceived learning, showed significant estimates of the variance in intercepts across participants in both samples $(p<0.001)$. The final model indicates that in both data sets (Tables 3,4$)$, the use of metaphors has a significant and positive relationship to perceived learning, $\mathrm{F}(1$, $155.23)=12.72, p<0.001$ at sample 1 and sample $2 \mathrm{~F}(1,72.22)=20.29, p<0.001$. In addition, the control variables for gender, nationality, discipline, and subteam membership had a non-significant relationship to perceived learning in both samples.

\section{Discussion}

The importance of multidisciplinary design student teams in education, and the relative challenge of communication among their functionally diverse students (e.g., Mannix and Neale 2005), makes it necessary to understand factors that influence learning within these teams. This study examined how communication modes relate to individual learning through student to student interaction in multidisciplinary design teams. Generally, the results indicate that metaphorical communication is related to perceived learning beyond the effects of narratives and visualization across both samples, while the effectiveness of narratives and visualization varied in the two samples. In Sample 2, both narratives and visualization had a positive relationship to learning, although the magnitude of their effects were diminished when the metaphors were introduced. Sample 1 included a positive relationship between narratives and learning (but no significant relationship for visualization); however, this effect became non-significant when metaphors were introduced. The model also showed that none of the control variables in either sample had a significant relationship with perceived individual learning. Overall, these results indicate that multidisciplinary design teams and the students in them may improve their learning through awareness and use of various communication modes, which can enhance the way information is represented and structured within multidisciplinary design student teams.

We posited that metaphors used in communication among members would relate to learning, theoretically through facilitating the transfer of knowledge by comparing a known base to an intended target. As expected, we found that frequent use of metaphors in communication relationships supports perceptions of individual learning. This is in line 


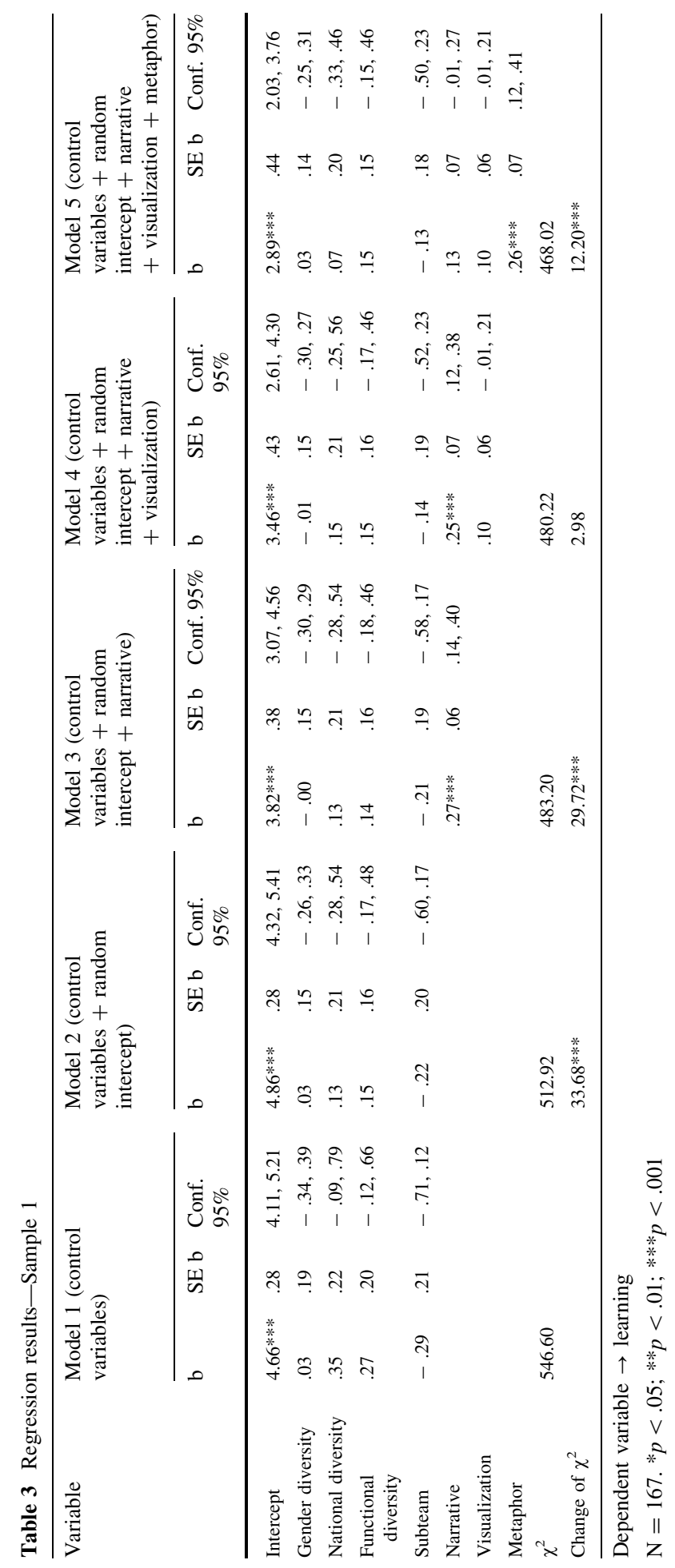




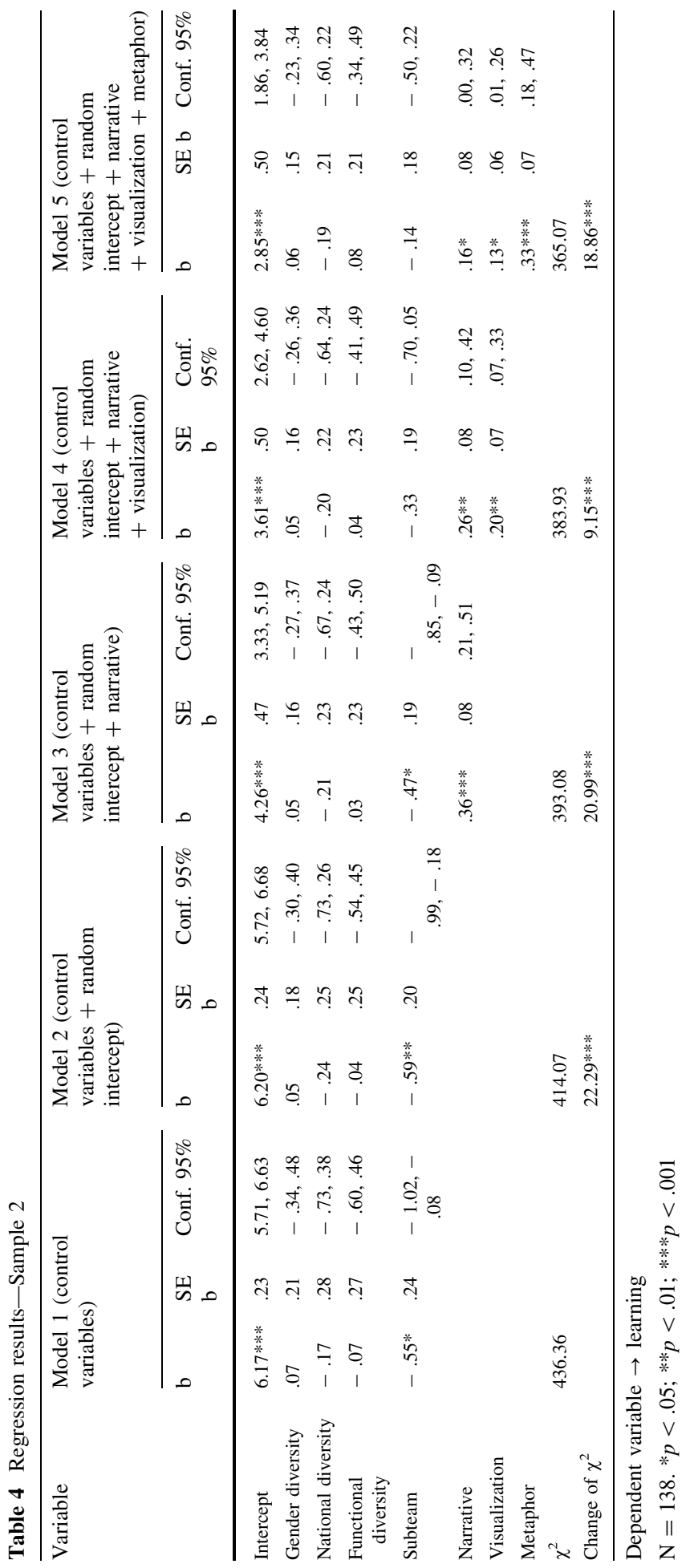


with previous research showing that analogical training in experimental settings can support learning (Loewenstein et al. 2003). It seems that metaphors can be helpful, as explanatory vehicles, in clarifying discipline-specific knowledge and skills and, therefore, has the potential to improve learning in multidisciplinary design student teams.

In addition, visualization and narrative had a positive relationship to perceived learning in Sample 2. Finding some positive results for visualization was not surprising. There is quite an extensive literature on the positive effects of visualization in communication due to qualities that increase comprehension (Eppler and Platts 2009; Waisel et al. 2008). Similar to visualization, narratives can support knowledge sharing (Orr 1990; Patriotta 2003). Orr (1990) found in his ethnographic study that narratives can provide a rich description of the problem and through it improve understanding. It seems that this effect also occurred in these settings with student design teams working on client projects. The results being weaker as compared with metaphors might be due to the persuasive aspect of metaphors. Geiger (2010) found that narratives alone might not be enough for knowledge exchange and that an argumentation mode might also be needed for knowledge transfer.

It may seem surprising that we did not find any significant relationship between knowledge held in common within dyads and learning. However, this is in line with the team diversity literature, which yields mixed results for team diversity and various performance outcomes, because while diversity is needed for knowledge exchange, it may also make that exchange more difficult (for a review see Mannix and Neale 2005). In our samples, neither homogenous nor heterogeneous backgrounds of subteam communication dyads had any association (positive or negative) with learning. It may be that although the homogenous dyads understood each other better, they did not learn as much from each other. In other words, although the learning process might have been better among similar knowledge dyads compared with dissimilar knowledge dyads, the learning potential was lower compared with dissimilar communication ties. Future researchers might want to examine the conditions under which individual learning is more likely to occur in diverse dyads. The low correlation between metaphors and common knowledge attributes might indicate that metaphors are a moderator of the relationship between diversity and learning.

\section{Metaphors in learning might be widely applicable}

This study indicates a positive relationship between metaphors and learning, beyond the effects of narratives and visualization, in two separate samples of multidisciplinary student design teams. In spite of the differences in the variables in these two samples and the resulting separate analysis, the patterns of results are quite similar. This is in line with studies on analogical encoding, furthering the evidence that demonstrates the wide applicability of metaphors and analogies (Gentner et al. 2003).

The level of national diversity within dyads did not have a relationship with learning in both samples. It might be that students are able to decontextualize their national knowledge, like their functional knowledge, by linking their national-specific knowledge to the nationality of the receiver and thus transferring knowledge. This might be the case in particular for students with a global mindset that highlights the cognitive ability to manage and integrate various national perspectives (Levy et al. 2007).

Both samples included many exchange students, and both the lectures and the teamwork exchanges were in English. If the course had been in a different language, the results might have looked different. Research has shown that learning styles vary according to the individual cultural values (Holtbrügge and Mohr 2010). Further, some researchers have argued that culture affects beliefs in knowledge and learning (Hardy and Tolhurst 2014). 
One reason for the findings of this study might be that we were exploring knowledge sharing and not in culture. Hence individual nationality rather than cultural values was used as a proxy for knowledge. Research that found differences focused on cultural values rather than on nationality (c.f. Holtbrügge and Mohr 2010). Future research might want to investigate cultural aspects and the use of metaphors in teams.

\section{Conclusion}

In this study we explored narratives, visualizations, and metaphors and their relationship to perceived learning in the context of multidisciplinary design teams. Our results show that metaphorical communication is related to learning, even beyond the effects of narratives and visualization. The findings of this study suggest that lecturers should teach metaphor use as an effective communication mode for multidisciplinary design teams. Multidisciplinary teams are also an important phenomenon in business organizations, particularly for design-led approaches to problem solving, and training students in communication skills based on the use of metaphors, visualization, and narratives may increase their future success in the workplace (Design Council 2010).

There are books available on how to develop metaphors in the classroom (e.g. Wormeli 2009). Much training in soft skills has focused on active listening and careful explanation of all information, but has rarely suggested the use of specific communication mode within multidisciplinary design student teams. Students could potentially benefit from learning more efficient communication modes, not only within the classroom, but also at work (Bedwell et al. 2014). Various research has shown that metaphors improve communication in a wide variety of settings (Pollack 2014). At the same time, the findings might be transferable to teachers and teaching in the classroom. Textbooks already use metaphors to improve students' understanding (Klenk and Forbus 2009). In these diverse environments, it might be helpful if teachers were more explicit in their teaching. One way to improve our communication could also be the use of metaphors in the classroom (c.f. Wormeli 2009).

We investigated individually reported (perceived) learning through a dyadic relationship, rather than independent assessments of learning measured against standards. As mentioned above, self-reported measures of learning are appropriate for educational, project-focused studies (e.g., Lim and Morris 2006; van Breukelen et al. 2017). Reported learning is particularly suitable for our research question and study design, because our interest is whether team members believe that they have learned from other members' use of particular communication modes (narratives, visualization, and metaphors). While measuring other forms of learning may also be useful, it is not clear that such measures would effectively capture learning stemming from the student-to-student interaction (cf. Bowman 2010). For instance, assessments gathered as part of the course assignments (e.g. project outcome, final grade) would measure a variety of determinants of individual learning, beyond our scope of interest in student to student interaction, such as self-study (student to content interaction) and lectures (student to teacher interaction). Further, a direct measure would not be likely to capture the breadth of learning that may occur as students learn from other students who are using particular communication modes. Such as cognitive learning, affective learning, and/or skills-based learning. Given the scope of the project (i.e. developing a concept), and the breadth of the team (i.e. very diverse, functionally and otherwise), it might not be feasible to develop a direct, objective assessment that represents the various aspects of learning. Nonetheless, future research might want to 
investigate further the relationships of communication modes and other indicators and forms of learning.

There are a great many communication modes, tools, and techniques that may be worthy of investigation. For this study, we focused on three modes connected to learning which have been particularly noteworthy in design projects-metaphors, narratives and visualizations. We acknowledge that there might be other communication modes, such as interpretive presentation modes or dialectical debate, in future research.

Previous research suggests that novices such as students struggle to use metaphors properly (Forbus et al. 1995; Novick 1988; Novick and Holyoak 1991). Also, within nationally diverse dyads, it could be that metaphors are misunderstood because they can have different meanings in different cultures (Gibson and Zellmer-Bruhn 2001). Nevertheless, learning in case study research showed that metaphors benefit actual learning (Gentner et al. 2003). In addition, it might be that perceived learning contributes indirectly to actual learning by increasing students' motivation, which in turn could stimulate further study and learning. Future research might further examine the relationship between metaphors and learning against external standards in multidisciplinary design student teams. Such approaches could also go further in assessing particular communication instances, specific information exchanged, and perhaps reported shifts in mental models.

Open Access This article is distributed under the terms of the Creative Commons Attribution 4.0 International License (http://creativecommons.org/licenses/by/4.0/), which permits unrestricted use, distribution, and reproduction in any medium, provided you give appropriate credit to the original author(s) and the source, provide a link to the Creative Commons license, and indicate if changes were made.

\section{References}

Argote, L., \& Epple, D. (1990). Learning curves in manufacturing. Science, 247(4945), 920-924.

Argote, L., Gruenfeld, D., \& Naquin, C. (2012). Group learnings in organizations. In M. E. Turner (Ed.), Groups at work: Theory and research (pp. 369-411). New York, NY: Routledge.

Ball, L. J., \& Christensen, B. T. (2009). Analogical reasoning and mental simulation in design: Two strategies linked to uncertainty resolution. Design Studies, 30(2), 169-186.

Ball, L. J., Ormerod, T. C., \& Morley, N. J. (2004). Spontaneous analogising in engineering design: A comparative analysis of experts and novices. Design Studies, 25(5), 495-508.

Bearman, C. R., Ball, L. J., \& Ormerod, T. C. (2007). The structure and function of spontaneous analogising in domain-based problem solving. Thinking \& Reasoning, 13(3), 273-294.

Bedwell, W. L., Fiore, S. M., \& Salas, E. (2014). Developing the future workforce: An approach for integrating interpersonal skills into the MBA classroom. Academy of Management Learning \& Education, 13(2), 171-186.

Benbunan-Fich, R. (2010). Is self-reported learning a proxy metric for learning? Perspectives from the information systems literature. Academy of Management Learning \& Education, 9(2), 321-328.

Blanchette, I., \& Dunbar, K. (2001). Analogy use in naturalistic settings: The influence of audience, emotion, and goals. Memory \& Cognition, 29(5), 730-735.

Booth, J. W., Taborda, E. A., Ramani, K., \& Reid, T. (2016). Interventions for teaching sketching skills and reducing inhibition for novice engineering designers. Design Studies, 43, 1-23.

Bowman, N. A. (2010). Assessing learning and development among diverse college students. New Directions for Institutional Research, 2010(145), 53-71.

Carlson, J. R., \& Zmud, R. W. (1999). Channel expansion theory and the experiential nature of media richness perceptions. Academy of Management Journal, 42(2), 153-170.

Casakin, H. P. (2007). Factors of metaphors in design problem-solving: Implications for design creativity. International Journal of Design, 1(2), 23-35.

Casakin, H. P. (2012). An empirical assessment of metaphor use in the design studio: analysis, reflection and restructuring of architectural design. International Journal of Technology and Design Education, 22(3), 329-344. 
Casakin, H., \& Goldschmidt, G. (1999). Expertise and the use of visual analogy: Implications for design education. Design Studies, 20(2), 153-175.

Cho, J. Y., Cho, M.-H., \& Kozinets, N. (2015). Does the medium matter in collaboration? Using visually supported collaboration technology in an interior design studio. International Journal of Technology and Design Education, 26(4), 567-586.

Christensen, B. T., \& Ball, L. J. (2016). Creative analogy use in a heterogeneous design team: The pervasive role of background domain knowledge. Design Studies, 46, 38-58.

Clark, M. A., Anand, V., \& Roberson, L. (2000). Resolving meaning: Interpretation in diverse decisionmaking groups. Group Dynamics: Theory, Research, and Practice, 4(3), 211-221.

Daft, R. L., \& Lengel, R. H. (1984). Information richness: A new approach to managerial behavior and organizational design. In L. L. Cummings \& B. M. Staw (Eds.), Research in organizational behavior 6 (pp. 191-233). Homewood, IL: JAI Press.

Design Council. (2007). Lessons from America: Report on the design council. London: Higher Education Funding Council for England.

Design Council (2010). Multi-disciplinary design education in the UK. http://www.designcouncil.org.uk/ sites/default/files/asset/document/multi-disciplinary-design-education.pdf.

Do, E. Y.-L., Gross, M. D., Neiman, B., \& Zimring, C. (2000). Intentions in and relations among design drawings. Design Studies, 21(5), 483-503.

Dougherty, D. (1992). Interpretive barriers to successful product innovation in large firms. Organization Science, 3(2), 179-202.

Douglas, M. (1987). How institutions think. London: Routledge and Kegan Paul.

Edmondson, A. (1999). Psychological safety and learning behavior in work teams. Administrative Science Quarterly, 44(2), 350-383.

Eppler, M. J., \& Platts, K. W. (2009). Visual strategizing: The systematic use of visualization in the strategic-planning process. Long Range Planning, 42(1), 42-74.

Espinosa, J. A., \& Clark, M. A. (2014). Team knowledge representation: A network perspective. Human Factors, 56(2), 333-348.

Fliaster, A., \& Schloderer, F. (2010). Dyadic ties among employees: Empirical analysis of creative performance and efficiency. Human Relations, 63(10), 1513-1540.

Forbus, K. D., Gentner, D., \& Law, K. (1995). MAC/FAC: A model of similarity based retrieval. Cognitive Science, 19(2), 141-205.

Gagne, R. M. (1984). Learning outcomes and their effects: Useful categories of human performance. American Psychologist, 39(4), 377-385.

Geiger, D. (2010). The role of argument and narration in knowledge sharing: Coping with context, validity, and coherence. Schmalenbach Business Review, 62(3), 291-316.

Gentner, D. (1998). Analogy. In W. Bechtel \& G. Graham (Eds.), A companion to cognitive science (pp. 107-113). Oxford: Blackwell.

Gentner, D., Bowdle, B., Wolff, P., \& Boronat, C. (2001). Metaphor is like analogy. In D. Gentner, K. J. Holyoak, \& B. N. Kokinov (Eds.), The analogical mind: Perspectives from cognitive science (pp. 199-253). Cambridge: MIT Press.

Gentner, D., Falkenhainer, B., \& Skorstad, J. (1988). Viewing metaphor as analogy. In D. H. Helman (Ed.), Analogical reasoning: Perspectives of artificial intelligence, cognitive science and philosophy (pp. 171-177). Dordrecht: Kluwer.

Gentner, D., Loewenstein, J., \& Thompson, L. (2003). Learning and transfer: A general role for analogical encoding. Journal of Educational Psychology, 95(2), 393-408.

Gibson, C. B., \& Zellmer-Bruhn, M. E. (2001). Metaphors and meaning: An intercultural analysis of the concept of teamwork. Administrative Science Quarterly, 46(2), 274-303.

Goode, M. R., Dahl, D. W., \& Moreau, C. P. (2010). The effect of experiential analogies on consumer perceptions and attitudes. Journal of Marketing Research, 47(2), 274-286.

Gregan-Paxton, J., \& John, D. R. (1997). Consumer learning by analogy: A model of internal knowledge transfer. Journal of Consumer Research, 24(3), 266-284.

Gruenther, K., Bailey, R., Wilson, J., Plucker, C., \& Hashmi, H. (2009). The influence of prior industry experience and multidisciplinary teamwork on student design learning in a capstone design course. Design Studies, 30(6), 721-736.

Haglund, J. (2017). Good use of a "Bad" metaphor. Science \& Education, 26(3-4), 205-214.

Hardy, C., \& Tolhurst, D. (2014). Epistemological beliefs and cultural diversity matters in management education and learning: A critical review and future directions. Academy of Management Learning \& Education, 13(2), 265-289.

Hekkert, P., \& Cila, N. (2015). Handle with care! Why and how designers make use of product metaphors. Design Studies, 40, 196-217. 
Hey, J., Linsey, J., Agogino, A. M., \& Wood, K. L. (2008). Analogies and metaphors in creative design. International Journal of Engineering Education, 24(2), 283-294.

Hinsz, V. B., Tindale, S., \& Vollrath, D. A. (1997). The emerging conceptualization of groups as information processors. Psychological Bulletin, 121(1), 43-64.

Holtbrügge, D., \& Mohr, A. T. (2010). Cultural determinants of learning style preferences. Academy of Management Learning \& Education, 9(4), 622-637.

Jassawalla, A., Sashittal, H., \& Malshe, A. (2009). Students' perceptions of social loafing: Its antecedents and consequences in undergraduate business classroom teams. Academy of Management Learning \& Education, 8, 42-54.

Kalogerakis, K., Lüthje, C., \& Herstatt, C. (2010). Developing innovations based on analogies: Experience from design and engineering consultants. Journal of Product Innovation Management, 27(3), 418-436.

Kampourakis, K. (2016). The bad use of metaphors and the use of bad metaphors. Science \& Education, 25(9-10), 947-949.

Kenny, D. A., Kashy, D. A., Cook, W. L., \& Simpson, J. A. (2006). Dyadic data analysis (1st ed.). New York: Guilford Press.

Klenk, M., \& Forbus, K. (2009). Domain transfer via cross-domain analogy. Cognitive Systems Research, 10(3), 240-250.

Kraiger, K., Ford, J. K., \& Salas, E. (1993). Application of cognitive, skill-based, and affective theories of learning outcomes to new methods of training evaluation. Journal of Applied Psychology, 78(2), 311-328.

Kreft, I. G. G., \& de Leeuw, J. (1998). Introducing multilevel modeling (1st ed.). London: SAGE Publications Ltd.

Levy, O., Beechler, S., Taylor, S., \& Boyacigiller, N. A. (2007). What we talk about when we talk about "global mindset": Managerial cognition in multinational corporations. Journal of International Business Studies, 38(2), 231-258.

Lewis, K. (2004). Knowledge and performance in knowledge-worker teams: A longitudinal study of transactive memory systems. Management Science, 50(11), 1519-1533.

Lim, D. H., \& Morris, M. L. (2006). Influence of trainee characteristics, instructional satisfaction, and organizational climate on perceived learning and training transfer. Human Resource Development Quarterly, 17(1), 85-115.

Lloyd, P. (2000). Storytelling and the development of discourse in the engineering design process. Design Studies, 21(4), 357-373.

Loewenstein, J., Thompson, L., \& Gentner, D. (1999). Analogical encoding facilitates knowledge transfer in negotiation. Psychonomic Bulletin \& Review, 6(4), 586-597.

Loewenstein, J., Thompson, L., \& Gentner, D. (2003). Analogical learning in negotiation teams: Comparing cases promotes learning and transfer. Academy of Management Learning \& Education, 2(2), 119-127.

Maas, C. J., \& Hox, J. J. (2005). Sufficient sample sizes for multilevel modeling. Methodology, 1(3), 86-92.

Madsen, K. H. (1994). A guide to metaphorical design. Communications of the ACM, 37(12), 57-62.

Mannix, E., \& Neale, M. A. (2005). What differences make a difference? Psychological Science in the Public Interest, 6(2), 31-55.

McMahon M, Bhamra T (2016) Mapping the journey: Visualising collaborative experiences for sustainable design education. International Journal of Technology and Design Education, 1-15.

Miller, W. S., \& Summers, J. D. (2013). Investigating the use of design methods by capstone design students at Clemson University. International Journal of Technology and Design Education, 23(4), 1079-1091.

Moreno, D. P., Hernández, A. A., Yang, M. C., Otto, K. N., Hölttä-Otto, K., Linsey, J. S., et al. (2014). Fundamental studies in design-by-analogy: A focus on domain-knowledge experts and applications to transactional design problems. Design Studies, 35(3), 232-272.

Novick, L. R. (1988). Analogical transfer, problem similarity, and expertise. Journal of Experimental Psychology. Learning, Memory, and Cognition, 14(3), 510-520.

Novick, L. R., \& Holyoak, K. J. (1991). Mathematical problem solving by analogy. Journal of Experimental Psychology. Learning, Memory, and Cognition, 17(3), 398.

Onega, S. G., \& Landa, J. A. (Eds.). (1996). Narratology: An introduction. London: Longman.

Orr, J. (1990). Sharing knowledge, celebrating identity: War stories and community memory in a service culture. In D. Middleton \& D. Edwards (Eds.), Collective remembering (pp. 169-189). London: Sage.

Paletz, S. B. F., Schunn, C. D., \& Kim, K. H. (2013). The interplay of conflict and analogy in multidisciplinary teams. Cognition, 126(1), 1-19.

Patriotta, G. (2003). Sensemaking on the shop floor: Narratives of knowledge in organizations. Journal of Management Studies, 40(2), 349-375.

Pei, E., Campbell, I., \& Evans, M. (2011). A taxonomic classification of visual design representations used by industrial designers and engineering designers. The Design Journal, 14(1), 64-91. 
Pollack, J. (2014). Shortcut: How analogies reveal connections, spark innovation, and sell our greatest ideas. New York: Avery Publishing Group.

Quigley, N. R., Tesluk, P. E., Locke, E. A., \& Bartol, K. M. (2007). A multilevel investigation of the motivational mechanisms underlying knowledge sharing and performance. Organization Science, $18(1), 71-88$.

Reagans, R., \& McEvily, B. (2003). Network structure and knowledge transfer: The effects of cohesion and range. Administrative Science Quarterly, 48(2), 240-267.

Silberstang, J., \& London, M. (2009). How groups learn: The role of communication patterns, cue recognition, context facility, and cultural intelligence. Human Resource Development Review, 8(3), $327-349$.

Turner, S., \& Turner, P. (2003). Telling tales: Understanding the role of narrative in the design of taxonomic software. Design Studies, 24(6), 537-547.

van Breukelen, D. H. J., de Vries, M. J., \& Schure, F. A. (2017). Concept learning by direct current design challenges in secondary education. International Journal of Technology and Design Education, 27(3), 407-430.

Venkataramani, V., \& Dalal, R. S. (2007). Who helps and harms whom? Relational antecedents of interpersonal helping and harming in organizations. Journal of Applied Psychology, 92(4), 952-966.

Waisel, L. B., Wallace, W. A., \& Willemain, T. R. (2008). Visualization and model formulation: An analysis of the sketches of expert modellers. The Journal of the Operational Research Society, 59(3), $353-361$.

Wasserman, S., \& Faust, K. (1994). Social network analysis: Methods and applications. New York: Cambridge University Press.

Wilson, J. M., Goodman, P. S., \& Cronin, M. A. (2007). Group learning. Academy of Management Review, 32(4), 1041-1059.

Wormeli, R. (2009). Metaphors \& analogies: Power tools for teaching any subject. Portland: Stenhouse Publishers.

Zhao, H., Seibert, S. E., \& Hills, G. E. (2005). The mediating role of self-efficacy in the development of entrepreneurial intentions. Journal of Applied Psychology, 90(6), 1265-1272.

Zurlo, F., \& Cautela, C. (2014). Design strategies in different narrative frames. Design Issues, 30(1), 19-35. 